\title{
A Conceptual People-Centric Framework for Sustainable Operational Excellence
}

\author{
Rapinder Sawhney ${ }^{1}$, Samuel Treviño-Martinez ${ }^{1 *}$, Enrique Macias de Anda1, \\ Guilherme Luz Tortorella², Omid Pourkhalili1 \\ ${ }^{1}$ University of Tennessee, Knoxville, TN, USA \\ ${ }^{2}$ Universidade Federal de Santa Catarina, Florianópolis, Brazil \\ Email: sawhney@utk.edu, ^strevin1@vols.utk.edu, emaciasd@utk.edu, gtortorella@bol.com.br, omid@vols.utk.edu
}

How to cite this paper: Sawhney, R., Treviño-Martinez, S., de Anda, E. M., Tortorella, G. L., \& Pourkhalili, O. (2020). A Conceptual People-Centric Framework for Sustainable Operational Excellence. Open Journal of Business and Management, 8, 1034-1058. https://doi.org/10.4236/ojbm.2020.83066

Received: February 14, 2020

Accepted: April 10, 2020

Published: April 13, 2020

Copyright $\odot 2020$ by author(s) and Scientific Research Publishing Inc. This work is licensed under the Creative Commons Attribution International License (CC BY 4.0).

http://creativecommons.org/licenses/by/4.0/

\begin{abstract}
Existing Lean Production (LP) roadmaps tend to solely focus on a set of pre-determined tools, techniques and training, disregarding the well-being of individuals involved in the system that will be affected by the changes in a LP implementation. Such myopic approach generates conflicts derived from a misalignment between organization and employee interests, which entails the failures of LP implementation. This study aims at proposing a framework to guide and sustain LP based on a systematic approach that balances people and productivity while improving the quality of life. The systematic approach, referred as the People-Centric Sustainable Operational Excellence Model, is outlined in the form of four modules addressing each of the propositions identified in the literature. Besides its academic contribution by adding to the body of knowledge such perspective into LP implementation, this study also has practical implications as it provides generalizable LP implementation steps different from other approaches.
\end{abstract}

\section{Keywords}

Lean, Reliability, Productivity, Operational Excellence, Employee

Engagement, People-Centric

\section{Introduction}

Manufacturing improvement methodologies originally conceived in Toyota Production Systems (TPS) have gained worldwide attention in the last 40 years (Ohno, 1988; Monden, 2011). The adoption of such practices and principles has been referred to as Lean Production (LP). The core idea of LP is to systematically reduce waste in an organization's value stream through people engagement (Bha- 
sin, 2008). Several researchers (Shah \& Ward, 2003; Fullerton \& Wempe, 2009; Zhou, 2016) have shown evidence of operational and financial benefits from LP implementation, which has motivated interest and cross-sector dissemination. However, the inherent socio-technical changes entailed by LP implementation and sustainability have also had counterintuitive impacts on the way work is designed and employee motivation (Saurin \& Ferreira, 2009).

Bhasin (2008) stated that less than $10 \%$ of UK organizations accomplish successful LP implementations; while Lucey et al. (2005) indicated that, in a broader context, the index of successful changes into a lean organization barely achieves $20 \%$. In fact, Sezen et al. (2012) argued that many Western companies unsuccessfully tried to import TPS techniques to their production systems, neglecting the importance of the underlying sociocultural factors in the shift from a traditional mass-production model to a LP.

The motivation of this paper resides in placing the well-being of individuals involved in the systems that will be affected by the changes in a LP implementation. Inherently, the conflict originates within the perspectives of performance at work and quality of life of people. Principles related to employees' well-being and quality of life are usually misaligned with organizational expectations such as productivity and financial measures (Alagaraja \& Shuck, 2015). This results in unpleasant and stressful environments, where people are constantly pushed to achieve results at the expense of personal sacrifice (Harrison, 1997), diminishing organizational performance (Conti et al., 2006).

Quality of life in working environments has been extensively studied during the past decades (Biazzo \& Panizzolo, 2000; Hasle et al., 2012). However, studies that concurrently suggest a LP framework towards enhancing quality of life are still scarce or shallowly approach the topic. In that sense, our research adds to the body of knowledge by integrating such perspective into LP implementation. Based on the aforementioned argument, a research question can be raised: "how do organizations properly balance people and operations perspectives to successfully implement and sustain LP while improving quality of life?” To answer this question, this study aims to propose a model that guides LP implementation based on a systemic problem identification and solution by holding people at the center of the design.

The rest of this paper is structured as follows. Section 2 carries out a literature review on LP and provides four propositions describing key conditions in which an effective LP implementation is more likely to be sustained. Section 3 describes the proposed model and its modules while Section 4 discusses how this model can mitigate the current flaws evidenced in both theory and practice. Finally, Section 5 concludes the study indicating its limitations and future research opportunities.

\section{Literature Review}

A sustainable LP model requires addressing a balance between a system that is 
designed to optimize operational parameters (i.e. "the perfect operational system") and a system that focuses its operation on the people involved (i.e. "the perfect people system"). A perfect operational system requires key performance indicators such as the highest productivity while having no inventories as well as no backorders, maximum operational equipment effectiveness, zero defects quality levels, no absenteeism nor turnover, and perfectly predictable production schedules (Spear \& Bowen, 1999).

On a different perspective, the perfect people system in the context of the workplace requires a high quality of working life (Schouteten \& Benders, 2004) based on the principle of work-life balance (Gregory \& Milner, 2009). LP is a people driven system which can only prevail over time in continuous improvement with the full support of employees. Nevertheless, in reality, the changes introduced by LP together with inappropriate management decisions have led to higher levels of stress on shop floor workers (Conti et al., 2006) at the expense of work-life imbalances, in pursuit of the perfect operational system. Based on the evidenced issue, we will establish four propositions to serve as a basis for the conceptual framework in the subsequent sections.

\subsection{LP and Problem Definition and Selection}

One of the main issues raised in literature concerns the fact that most companies start their LP implementation without clearly understanding which and what kind of problems exist and can be addressed with LP implementation (Spear \& Bowen, 1999; Scherrer-Rathje, Boyle, \& Deflorin, 2009). In fact, the inherent continuous improvement efforts of a LP implementation are argued to be driven by cyclic experiments supported by a scientific method (Spear, 2009). However, to conduct truly scientific experimentations in an organizational environment, problems must be properly identified in order to meet the expected outcomes and to carry out the solution method (Puvanasvaran et al., 2008).

Misinterpretations of the actual problem can lead organizations to ineffective results, which may include the frustration of people and loss of confidence in the benefits of LP implementation (Shook, 2008). Hence, if problems are not clearly defined, erroneous continuous improvement initiatives take place consuming organizational resources (e.g. material, machines, people) that will not bring the expected impact in performance. The reoccurrence of this kind of issue can even establish a negative mindset that "lean does not work in my organization", leading to an unsuccessful implementation (Saad et al., 2013). The few studies similar to the present study approach this topic from a shallow perspective (Tortorella et al., 2015).

In addition, findings in the literature highlight that ambiguousness, lack of data, and unreliable communication have proven to negatively affect the project selection process in a LP implementation (Yang \& Hsieh, 2009). Turesky and Connell's (2010) findings revealed that project selection was frequently biased 
resulting in employee resistance and regression in project gains. In fact, large number of Small and Medium Enterprises (SMEs) are hindered strategically due to hurried approaches that do not embrace good resource utilization nor offer immediate returns whilst the implementation of LP (Saad et al., 2006). It is noteworthy that mechanisms to prioritize projects and standardized methods for a successful LP implementation have yet to emerge in the literature.

Derived from the above arguments, a first proposition is claimed:

Proposition 1: LP implementation is more likely to be sustained through a clearly defined, system-wide project, that minimizes the effort of the people.

\subsection{LP and Alignment with Organizational Goals}

Problem misconceptions can occur on different organizational levels, and within strategies, tactics and operations. This fact is usually observed when organizations fail to align strategic priorities and objectives (Giordani da Silveira et al., 2018). As guidelines are not well deployed within the organization, teams and employees end up focusing on misguided improvement indicators not directly connected with organizational goals. Hence, the misalignment among organization, teams and employees can reinforce divergent efforts that will not lead to systemic improvements (Jackson, 2006).

According to Womack and Jones (1990) a key aspect for Toyota's success is the clear and disseminated determination of its "True North". In other words, ensuring that the organizational issues are well-known across the organization underpins not only a more assertive problem identification but also helps to prioritize problems that should be addressed through a higher level of engagement from the people. The process of aligning and deploying objectives and policies in Toyota is called Hoshin Kanri (HK). HK is claimed to be the basis for successful organization-wide management (Akao, 1991), providing a systematic approach to integrate strategic objectives into daily routine management.

A big area of opportunity within both concepts is the definition of the appropriate set of Key Performance Indicators (KPIs) that would determine the success of LP implementation. Organizations typically focus in "lagging Indicators" as the measures to follow instead of "leading Indicators" (Bhasin, 2008). To keep track of LP progress a performance measurement system must be established (Smeds, 1994) focusing on "leading indicators"; however, a consensus on how to achieve this has not been reached. Attempts have been established in defining a set of metrics to measure LP (Narayanamurthy \& Gurumurthy, 2016; Yadav et al., 2017), but the delineated connection with the organizational outcomes and stakeholders is limited.

In this sense, based on the aforementioned arguments, the second proposition is:

Proposition 2: LP implementation is more likely to be sustained if the improvement indicators are properly aligned to organizations and people's interests. 


\subsection{LP, System Diagnosis and Enhancement of Flow}

Existing scientific literature provides an exhaustive description of tools and techniques associated with LP together with roadmaps for their implementation pursuing the enhancement of production systems (Feld, 2000; Russell \& Taylor, 2006). Despite such abundant evidence, there is a lack of a consensual method in guiding how LP initiatives should be implemented (Bhamu \& Singh Sangwan, 2014). Hence, one of the major mistakes in LP implementation is to solely focus on the adoption of practices rather than considering these practices as part of a system that seeks to solve the existing problems in the organization (Womack \& Jones, 1994). The misapplication of LP practices would only undermine its implementation, wasting efforts and resources resulting in undesired performances and frustration.

Several authors have proposed LP frameworks "bundling" the different LP practices in relationship to strategic programs in a LP implementation (Shah \& Ward, 2003; Belekoukias et al., 2014) while providing guidelines that have a hopeful impact on certain operational outcomes. Other authors have suggested models that facilitate the selection of LP practices given predefined characteristics that match the description of the manufacturing problem under study (Pavnascar et al., 2003; Matias et al., 2018). Nonetheless, they are deficient in understanding the "physics" of the system to improve. In addition, because there is not a universally accepted definition on the term of productivity (Almström \& Kinnandel, 2011), it becomes difficult to converge into a set of "rule of thumb" techniques for any LP initiative.

Moreover, LP initiatives typically tend to revolve around the enhancement of flow (Bhamu \& Singh Sangwan, 2014), disregarding the fact that variability and disruptions have been proven to always degrade the performance of a production system (Li \& Meerkov, 2000). Ultimately, such disconnection prevents organizations from deploying long-term reliable solutions. Hence, the adoption of LP initiatives should be problem-specific based on a scientific diagnosis that considers the dynamics that affect operational performance-flow efficiency and process reliability (Hopp \& Spearman, 2008), with the latter being of fundamental relevance before any attempt is conducted to improve the efficiency of the system.

Given such limitations, the following proposition is formulated:

Proposition 3: LP implementation is more likely to succeed if practices are adopted with a prior systematic diagnosis that underlines its behavior with respect to reliability.

\subsection{LP and Sustainability through People Engagement}

The discussion of individuals' values and beliefs on LP principles adoption has been examined from a diffuse and prolific perspective. Researchers (Losonci et al., 2011; Bortolotti et al., 2015) have emphasized that individuals' beliefs and values have a considerable impact on their perceptions for a successful lean im- 
plementation (Sawhney \& Chason, 2005). Successful organizations that operate and sustain LP are those that place emphasis on people and their behaviors and habits that will lead to an organizational cultural shift. More specifically, LP implementation entails a significant change from a traditional mass-production and untimely mindset to a collaborative, long-term and customer focused way of thinking. Such fundamental change is time-consuming and demands a high level of people engagement in order to pervasively impact the organization.

Theories of the effects of LP have evolved from the perception of an inherently harmful production system to the workforce, to a system that can have mixed effects depending on the management style and the way it is implemented (Jurburg et al., 2017). Furthermore, sustainability of LP is greatly threatened by the effects it causes on the mental health of employees, generally manifested as stress. Arguments related to LP and reduction of worker stress are conflicting (Conti et al., 2006) however more research concludes disagreement (Spithoven, 2001). When the impact is negative it indirectly affects both the morale of the employees and reliability of the system (Sawhney et al., 2010). Such fact highlights the need for a deeper understanding of LP sustainability through actively engaging people, denoting a systematic gap in literature.

At a more granular level, several studies have focused on the psychological, psychosocial, physical and/or physiological effects on people caused by the implementation of LP practices. As shown in Table 1, among the most common factors found by Koukoulaki (2014) and reported in the literature are high levels in either "work pace", "workload" or "time pressure"; increasing levels of Musculoskeletal Disorders (MSD's) derived from increased motion or poor ergonomic design; and an increase in either "job stress", "stress", "psychological strain" or "job strain". The evidence suggests that LP is still questionable in its contributions to improve the quality of life of the people involved in these systems, or even if people are given sufficient consideration.

In face of the evidenced issues, the following proposition is described:

Proposition 4: A transformational process based on LP is more likely to be sustained if the people are actively engaged, and their needs are considered to enhance their quality of life.

\section{Methodology}

A discipline that allows one to understand the aforementioned contingencies described in each of the four propositions, and their effects with respect to the ability of a system to sustain LP is within systems Thinking theory, more specifically, Systems Dynamics (Forrester, 1971).

Literature on System Dynamics offers multiple studies demonstrating how feedback loop control theory can be utilized to describe the behavior of a system over time (Sterman, 2000; Senge, 2006). Under this approach, we investigate the behavioral complexity in the dynamics of a system seeking to sustain LP. 
Table 1. Impacts of LP implementation on human factors.

\begin{tabular}{|c|c|c|c|c|c|c|c|c|c|c|c|c|c|c|c|c|c|c|c|c|c|}
\hline Factors & (1) & (2) & (3) & (4) & (5) & (6) & (7) & (8) & (9) & (10) & (11) & (12) & (13) & (14) & (15) & (16) & (17) & (18) & (19) & (20) & $(21)$ \\
\hline $\begin{array}{l}\text { 1. Faster work pace, } \\
\text { higher workload, } \\
\text { greater time pressure }\end{array}$ & & $\mathrm{x}$ & & $\mathrm{x}$ & & $\mathrm{x}$ & & $\mathrm{x}$ & $\mathrm{x}$ & $\mathrm{x}$ & $\mathrm{x}$ & & $\mathrm{x}$ & & & & $\mathrm{x}$ & $\mathrm{x}$ & & & \\
\hline $\begin{array}{l}\text { 2. Ergonomic stressors, } \\
\text { higher motion, MSD, } \\
\text { pain, injuries, } \\
\text { mechanical exposures }\end{array}$ & $\mathrm{x}$ & & $\mathrm{x}$ & & & & $\mathrm{x}$ & $\mathrm{x}$ & & & $\mathrm{x}$ & & & & $\mathrm{x}$ & $\mathrm{x}$ & $\mathrm{x}$ & & $\mathrm{x}$ & & \\
\hline $\begin{array}{l}\text { 3. Job stress, general stress, } \\
\text { psychological strain, } \\
\text { job strain }\end{array}$ & $\mathrm{x}$ & & & $\mathrm{x}$ & $\mathrm{x}$ & & $\mathrm{x}$ & & & & & & & $\mathrm{x}$ & & & & $\mathrm{x}$ & & & $\mathrm{x}$ \\
\hline $\begin{array}{l}\text { 4. Higher control, } \\
\text { job control }\end{array}$ & & & & & $\mathrm{x}$ & & & & & & $\mathrm{x}$ & $\mathrm{x}$ & $\mathrm{x}$ & & & & & & & $\mathrm{x}$ & \\
\hline $\begin{array}{l}\text { 5. Higher job demands, } \\
\text { work pressure }\end{array}$ & & & & & $\mathrm{x}$ & & & & $\mathrm{x}$ & & & & & & & $\mathrm{x}$ & & & $\mathrm{x}$ & & $\mathrm{x}$ \\
\hline $\begin{array}{l}\text { 6. Low autonomy, } \\
\text { low empowerment }\end{array}$ & & & & & & & & & & & & $\mathrm{x}$ & & $\mathrm{x}$ & & & & $\mathrm{x}$ & & & \\
\hline 7. Skill underutilization & & & & & & & & & & & & $\mathrm{x}$ & & $\mathrm{x}$ & & & & $\mathrm{x}$ & & & \\
\hline 8. Limited rest, exhaustion & & & & & & & & $\mathrm{x}$ & & & $\mathrm{x}$ & & & & & & & & & & \\
\hline 9. Low involvement & & & & & & & & & & & & $\mathrm{x}$ & & $\mathrm{x}$ & & & & & & $\mathrm{x}$ & \\
\hline $\begin{array}{l}\text { 10. Low job satisfaction, } \\
\text { low commitment }\end{array}$ & & & & & $\mathrm{x}$ & & & & & & & & & & & & & & & & \\
\hline $\begin{array}{l}\text { 11. Bad social climate, } \\
\text { little support and } \\
\text { development opportunities }\end{array}$ & & & & & & & & & & & & & $\mathrm{x}$ & & & & & & & & \\
\hline $\begin{array}{l}\text { 12. Low job clarity, } \\
\text { role conflict }\end{array}$ & & & & & & & & & & & & & & & & & & $\mathrm{x}$ & & & \\
\hline
\end{tabular}

Sources: (1) Berggren, 1991; (2) Babson, 1993; (3) Graham, 1995; (4) Mullarkey, Jackson, \& Parker, 1995; (5) Jackson \& Martin, 1996; (6) Lewchuk \& Robertson, 1996; (7) Adler, Goldoftas, \& Levine, 1997; (8) Bao, Winkel, Mathiassen, \& Shahnavaz, 1997; (9) Lewchuk \& Robertson, 1997; (10) Vendramin et al., 1998; (11) Lewchuk, Stewart, \& Yates, 2001; (12) Bruno \& Jordan, 2002; (13) Härenstam, Rydbeck, Johansson, Karlqvist, \& Wiklund, 2002; (14) Parker, 2003; (15) Brenner, Fairris, \& Ruser, 2004; (16) Leroyer, Kraemer-Heriaud, Marescaux, \& Frimat, 2006; (17) Mehri, 2006; (18) Sprigg \& Jackson, 2006; (19) Lloyd \& James, 2008; (20) Chay et al., 2015; (21) Khaba \& Bhar, 2018.

\subsection{A Systems Thinking Approach}

As evidenced in the literature, a system in which LP is adopted as means to increase efficiency leads to higher production pressures and faster work pace environments (Koukoulaki, 2014), creating a burden on people's quality of life. Thus, the Sustainability of LP requires a paradigm shift. A system not primarily focused on efficiency practices and productivity, but one in which the quality of life of people is the center of attention and is reinforced by the increased reliability of the process instead (Keyser \& Sawhney, 2013). Such system (Figure 1), illustrates the causal loop diagram of elements and interconnections (i.e. flows) that exists in each of the four propositions discussed in the literature: 1) problem definition and selection, 2) alignment with organizational goals, 3) system diagnosis and enhancement of flow, 4) and sustainability through people engagement. 


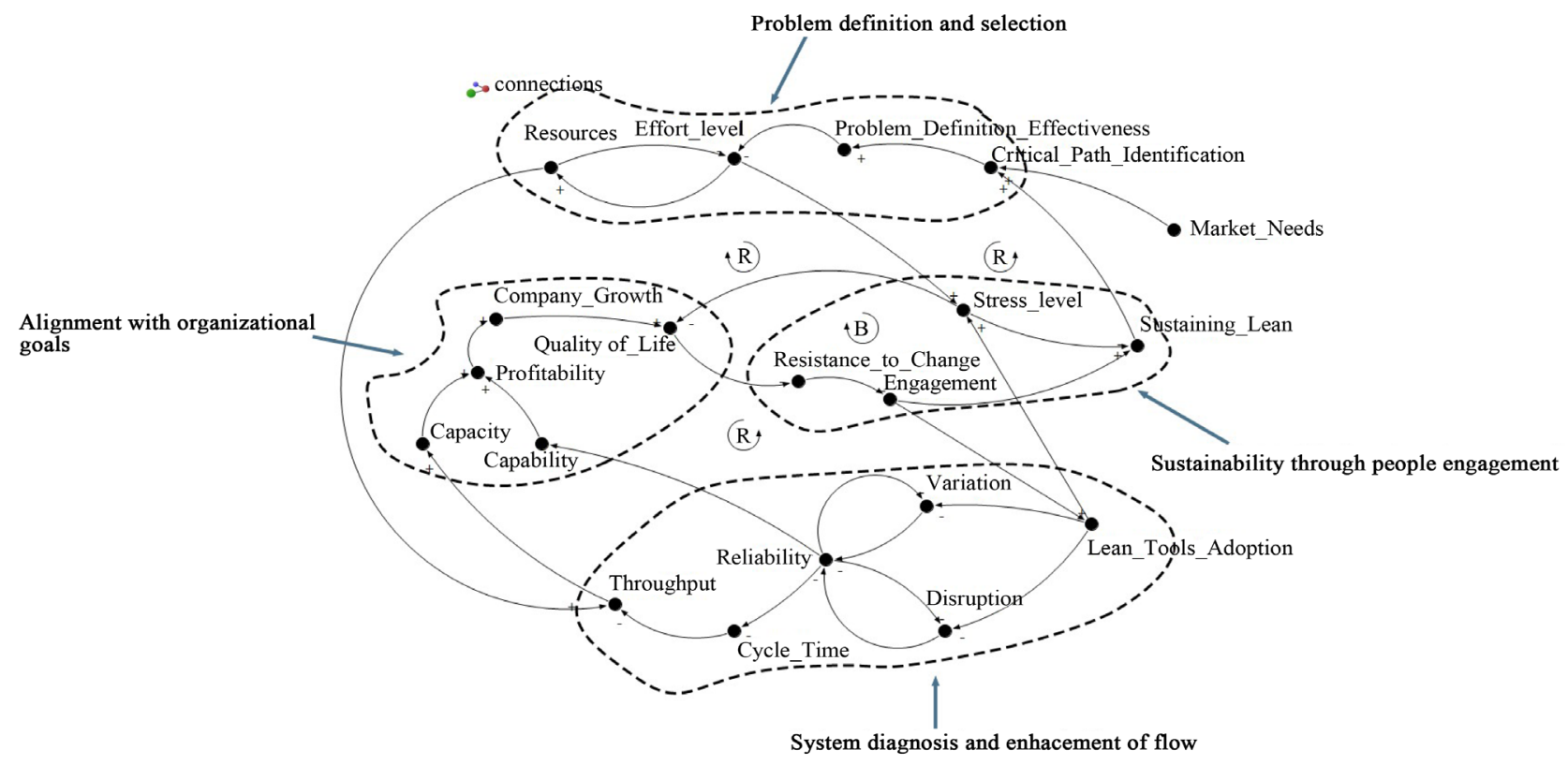

Figure 1. Systems thinking diagram in sustaining LP.

The system begins with an exogenous variable described as "Market needs" which resembles the Voice of the Customer (VOC) or Stakeholder Requirements. It ignites the search to improve the performance of the critical path of the system to the desired behavioral levels. Subsequently, the Critical Path Performance identification causes an increase on the effectiveness of the Problem Definition and, subsequently, a decrease on the Effort Level required from the system. Effort Levels dictate the amount of Resources demanded, which have a positive causal relationship with Effort Level. The rest of the interactions can be self-explanatory by observing the polarity of each causal link. A (+) symbol at the end of each arrow represents a positive interaction, meaning that a change in A produces a change in $B$ in the same direction. While a (-) symbol represents a negative interaction, such that a change in A produces a change in B in the opposite direction. The system also exhibits positive (reinforcing) and negative (balancing) feedback loops. By definition, balancing (B) feedback loops contain an odd number of negative (-) interactions and indicate a constrained or decaying behavior. On the other hand, an even number of negative (-) interactions or complete positive $(+)$ interactions within a loop generate reinforcing $(R)$ feedback structures which promote a positive growth behavior in a system (Kirkwood, 1998).

Considering the above, the proposed Methodology reduces the count of balancing structures to unrestraint the system and favor the growth of the stock Quality of Life. This is achieved by providing a mechanism to halt employee Stress Level via Reliability. Utilizing feedback loop theory, the dynamic behavior of Quality of Life and Sustaining Lean is expected to follow an S-shape function with oscillation, as opposed to an Overshoot and Collapse function found in the "Tragedy of Commons" archetype (Kim \& Anderson, 1998) which would re- 
semble systems that are based on Efficiency. Under the proposed approach, the Quality of Life grows in the beginning when the balancing feedback rate is low, and will oscillate after some time when some Stress is present, however, the rate of Stress gets reduced again as Reliability is enhanced in the system. In the long run, the state of the system is expected to reach an equilibrium at the carrying capacity of the system defined by the goals set in the organization. This paradigm shift based on Reliability, drifting away from current models based on Efficiency, is the logic behind the framework model proposed ahead.

\subsection{Proposed Model: A People-Centric Sustainable Operational Excellence Model}

Operational Excellence models that incorporate a robust engagement with people are limited in today's business environment, specifically addressing profit-sharing and co-ownership. These organizations grow through their connection with their local communities, possessing a strong influence in their strategy. These are a reflection of a humanistic value system that achieves through a socio-technical approach a concern for personal development and happiness (Mumford, 2006). Humanistic Management (HM), is a people-oriented management that seeks profits for human ends (Melé, 2016). The convergence of LP and HM through hybrid implementations merging LP principles from Toyota and $\mathrm{Hu}-$ man-Centered Work (HCW) from Volvo (Muffatto, 1999) have been studied mostly in organizations with European origin, finding a natural evolution in some Latin-American organizations (Davila \& Elvira, 2012). Recent focus on how LP supports HM has been placed on sustainability from the perspective of occupational health and safety (Camuffo, De Stefano, \& Paolino, 2017).

The proposed model to sustain LP presented in this paper considers a humanistic approach that also proposes benefits for the organization on a long term basis. This model is comprised of four main modules: 1) defining a system-based problem, 2) aligning continuous improvement with desired organizational outcomes, 3) system diagnosis and enhancement, and 4) sustaining via employee buy in (Figure 2). Each one of the modules considers people's needs and organizational interests, in order to achieve a successful LP implementation while fulfilling the aforementioned gaps. Further, it provides a systematic approach to address four main goals: 1) reduce resource and effort level by strategically defining the problem; 2) align efforts with system growth and competitiveness; 3 ) enhance capacity via reliability and flow; and 4) enhance employees' quality of life. It is noteworthy that the proposed framework in this study builds on the DRIVES (Define-Recognize-Identify-Visualize-Execute-Sustain) model which has been previously suggested by Sawhney and Macias de Anda (2016).

\subsubsection{Module 1-Defining a System-Based Problem}

The first module aims at identifying the most relevant problem to be solved by finding the critical path that constraints growth in the system. Thus, the system 


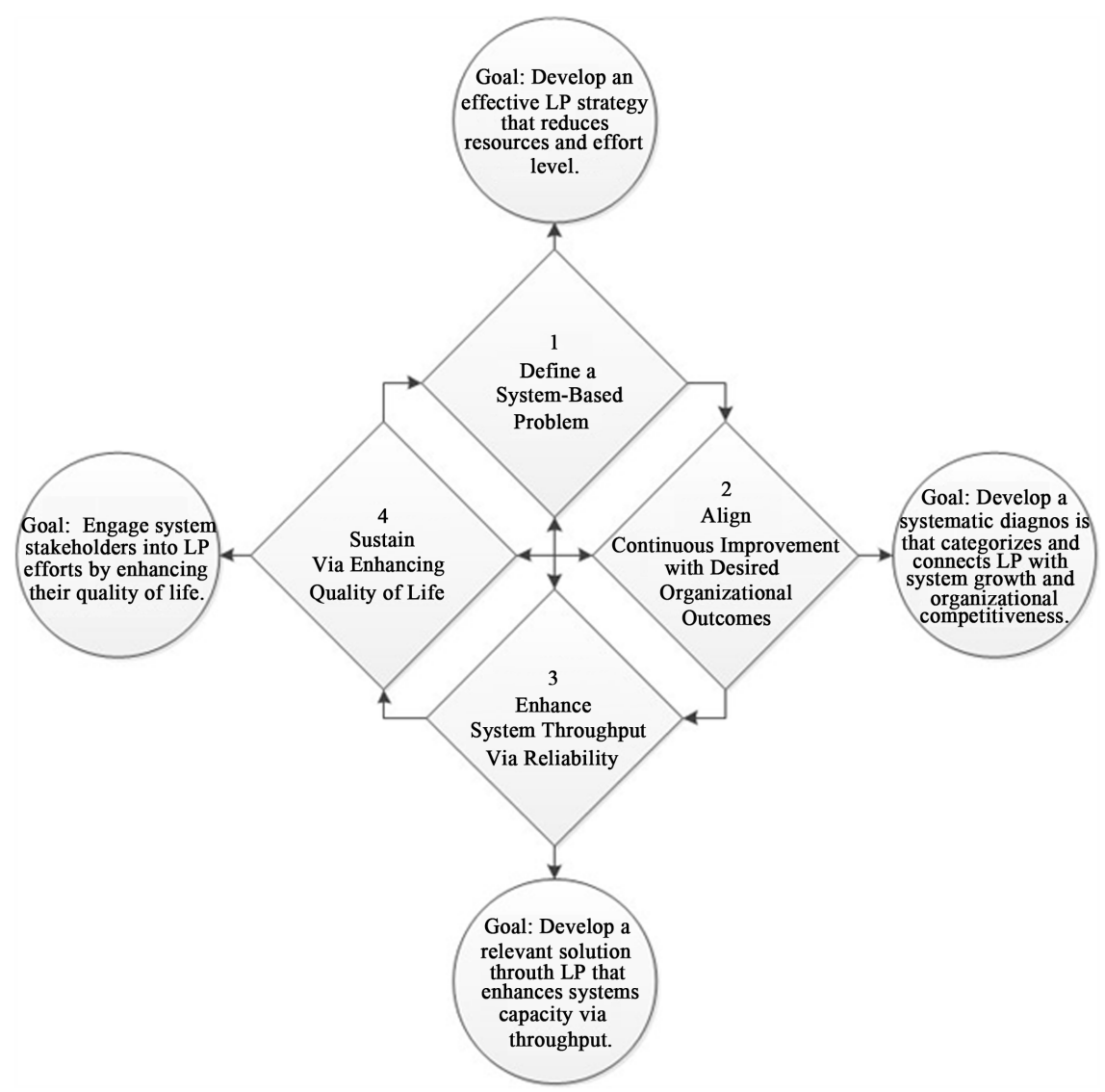

Figure 2. The people-centric sustainable operational excellence model.

under consideration should be visualized at the level of its constituent networks, sub-systems and processes. Hence, based on the DRIVES model, the bottleneck in the system and the critical path which contains the bottleneck is identified. Identifying the critical path requires the extraction of the key value streams by mapping the organizational sub-systems (e.g. human resources, sales, operations, $R \& D$, etc.) and their respective data and information. Further (Figure 3), the understanding of the contingencies of the organization allows to identify issues within key value streams that are systemically affecting company's performance and avoiding growth (Cameron \& Quinn, 2006).

Therefore, to properly identify a systemic problem a holistic perspective of the organization must be developed, enabling the comprehension of how the mitigation of the underlying problems on this critical path and its bottleneck could contribute to raise organizational performance level. The problem identification process considers both visualization and quantification of the workflow and includes both approaches underlying a conceptual model of production, which are either deterministic or stochastic processes.

Processes that are deterministic by nature are recognized by having constant production requirements, predefined product mix, and constant operational rates (e.g. welding robots). In contrary, stochastic processes have uncertainty 


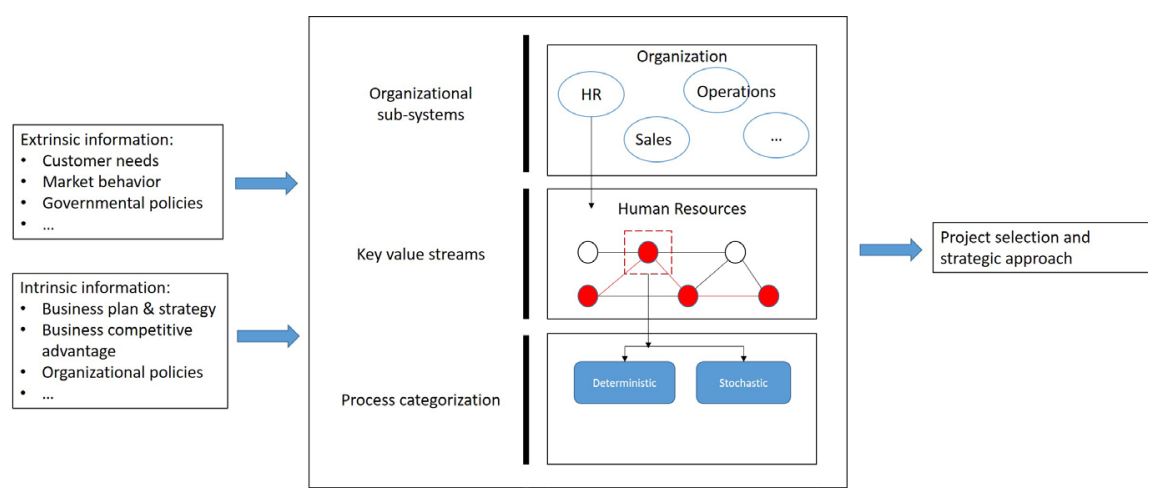

Figure 3. Defining a system-based problem.

attributes such as variations in processing times, variability in product mixes, uncertain demand, or uncertain flow routes (e.g. customized products).

This module is data-driven, unlike the usual problem identification based solely on vague and imprecise perceptions of senior management. Further, the expected output of this module provides a clear sense of urgency with regards to which problems must be prioritized from a system-based perspective. Inherently, the following questions must be answered to ultimately define the problem:

- Is the function that it is being worked on the true constraint to the growth of the system?

- What is the key value stream that drives growth?

- What is the critical path (network) of the key value stream?

- What is the category of the critical path, deterministic or stochastic?

The clarity on this output provides a more assertive concentration of efforts with a higher likelihood of effectively prioritizing the improvement initiatives that maximize the system's performance. In this research, we refer to the core performance measure as Throughput, and utilize Little's Law to define it (Little, 1961). We further decompose its formulation, Figure 4, to illustrate the prioritization of initiatives via flow, variation and disruption which lead to a reduction of the system's cycle time and in return maximize its throughput. Thus, deterministic processes should focus first on initiatives that minimize disruptions, then variation, and flow at the end. Conversely, stochastic processes should have LP strategies that first address the reduction of variation, then disruptions, and last flow. Hence, flow efficiency should occur after the process has been stabilized, and stabilization occurs via reliability by reduction of variation and disruptions.

The specific actions that follow such strategies are part of the problem diagnosis outputs described in module 3 of this framework. By properly defining the problems and the action plans in this proposed manner, organizations would not only avoid wasting time and resources on projects that will not lead to desired organizational goal, but would also mitigate the odds of frustrating and stressing people throughout the Lean journey (Antonelli \& Stadnicka, 2018). 


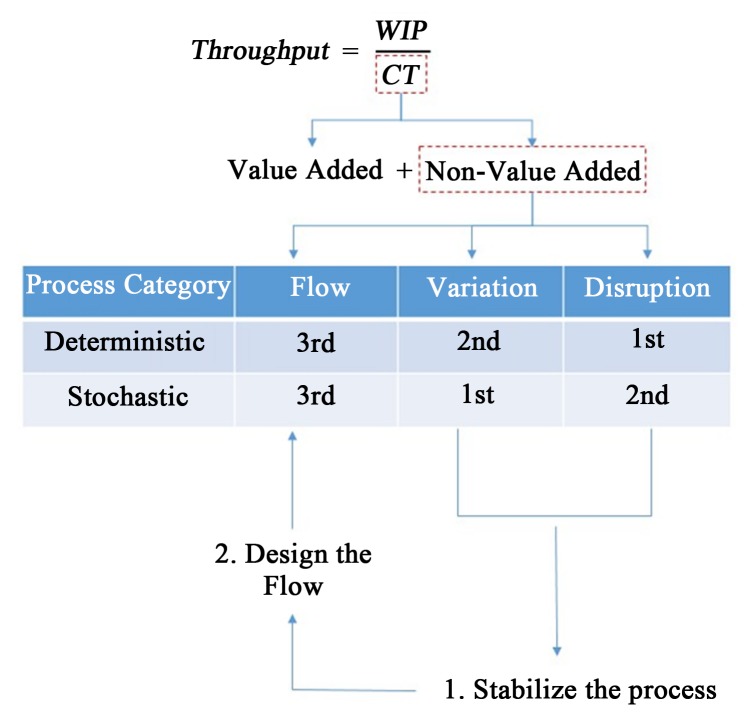

Figure 4. Process-based LP initiatives prioritization.

\subsubsection{Module 2-Aligning Continuous Improvement with Desired Organizational Outcomes}

The purpose of this module is to determine the performance metrics (leading indicators) which will be used to quantify the system's desired outcomes (lagging indicators). Thus, this module addresses the balance between both a system that is designed to optimize operational parameters (the perfect operational system), and a system that truly focuses its operation on the people involved (the perfect people system) in the establishment of lagging and leading indicators (Figure 5).

In the definition of such indicators, four levels of lagging outcomes are envisioned to be supported. At a level one, indicators should reflect the direct impact in increasing the capacity of the system by enhancing throughput. At a level two, the optimized capacity should enhance the financial performance (i.e. profitability) of the system. At a level three, financial health should provide the ability for the system to grow (i.e. market share). Finally, at a level four, growth must generate a positive impact in the society (i.e. reputation, quality of life of people) where the system resides. These lagging outcomes must be perfectly aligned and supported by key leading indicators.

An important step in defining the leading indicators of the system relies in the analysis of the behavior of throughput. It is known that a higher throughput provides the ability for organizations to increase their capacity to achieve the lagging outcomes mentioned above, and that throughput is enhanced by controlling its related process cycle time (Little, 1961). Further, based on the works of Hopp and Spearman (2008), and Womack and Jones (1990) it can be concluded that the biggest threat to cycle time relies in the effectiveness of the system. Since effectiveness is a function of reliability and flow, it becomes natural that the leading indicators must address the underlying variability, in the form of variation disruptions, and flow inefficiencies embedded in the process. 


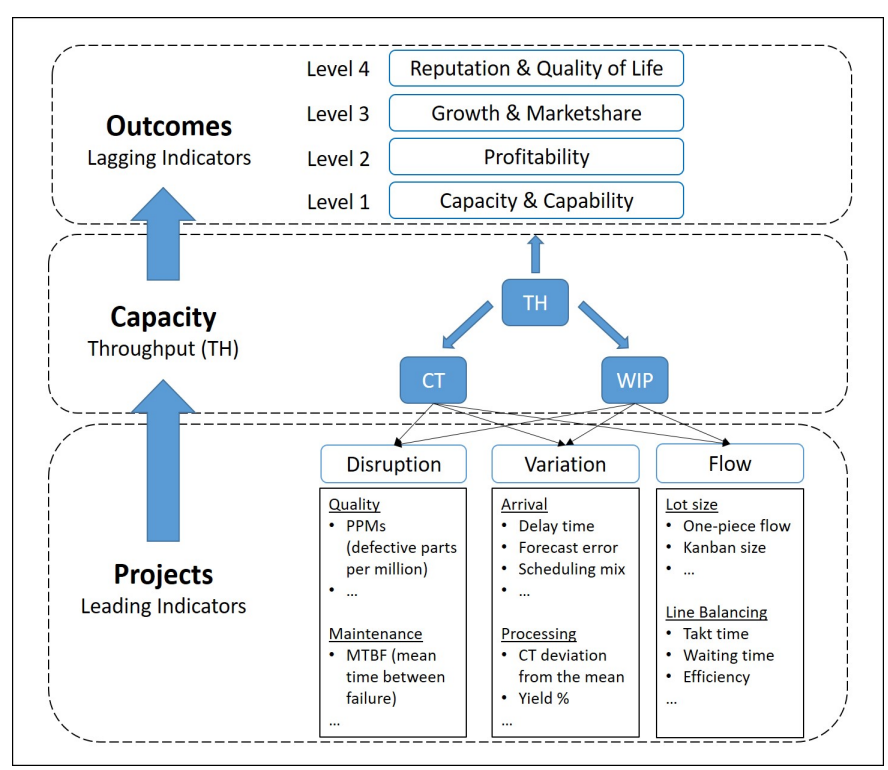

Figure 5. Aligning continuous improvement with desired organizational outcomes schematic.

The categorization of the selected process identified in module 1 allows the development of leading indicators at a high level of detail. Processes that are categorized as deterministic would include leading indicators to measure and control the level of disruptions in it (e.g. downtime, setup time, equipment reliability, worker absenteeism, material delays). On the other hand, processes that are categorized as stochastic would integrate leading indicators to measure and control its level of variability (e.g. forecast and production scheduling errors). Lastly, flow leading indicators (e.g. waiting time, inventory and efficiency) are defined for either processes. It is noteworthy to highlight that despite having such leading indicators at the process level, they must be tactically defined keeping in mind that at the end of the day such metrics must support the quality of life of its people.

\subsubsection{Module 3-System Diagnosis and Enhancement}

This module develops the solution to the issues presented in the prior modules. As discussed earlier, the development of a solution demands a clear understanding of performance metrics (leading indicators) to enhance based on the process attributes (i.e. deterministic or stochastic), and of the behavior and interaction of the factors contributing to the undesired effects in such metrics. Therefore, the main task at this point is to first stabilize the system, and subsequently improve flow.

The stabilization must be done with respect to the identified process attributes. Processes that are categorized as deterministic are enhanced by minimizing its disruptions-machine breakdowns, setups, worker absenteeism, or quality rejects-via reliability engineering. As idle time due to disruptions is reduced, the cycle time of the process is reduced as well, and in consequence throughput is 
increased. Hence, a reliable solution is required to possess four types of reliability in our model approach-People, Material, Equipment, and Information (PMEI). The imposition of this requirement provides a solution in which equipment is available during the specified time, a forecast and scheduling system is in place, material is provided to the right process at the right time and right quantity, and, in a significant departure from the Lean standard, workforce capabilities and skills are all factored into the definition of reliable systems (Keyser \& Sawhney, 2013).

On the other hand, processes that were categorized as stochastic are stabilized by minimizing their variation. The fact that variation has a negative resonance downstream in the system, causes a "snow ball" effect in which variation propagates to subsequent processes. Hence, targeting and minimizing the variation will not only enhance the ability of the system to match its expected cycle time locally, but across the entire system. Such stabilization of stochastic processes requires a quantitative analysis of the sources of variation related to the aforementioned reliability PMEI approach. Furthermore, decomposing variation into arrival and processing activities in the key-value stream permits managers to assertively locate and control such sources of variation.

Once the system has been stabilized and reliability engineering practices are in place, flow metrics can then be enhanced by redesigning flow such that the desired performance levels are achieved (Li et al., 2014). In the enhancement of flow, principles and techniques commonly known within JIT and Lean can be embraced (i.e. elimination of muda, pull, kanban, line balancing, etc.). Hence, process stability and enhancement of flow are the fundamental components in the development of a reliable solution (Figure 6).

The inclusion of stability as a significant step in the direction of developing LP solutions provides organizations the ability to create working environments that guarantee the satisfaction and well-being of employees, rather than just focusing on efficiency measures to enhance flow. Research suggests a negative impact on both working environment and employee health and well-being in conventional

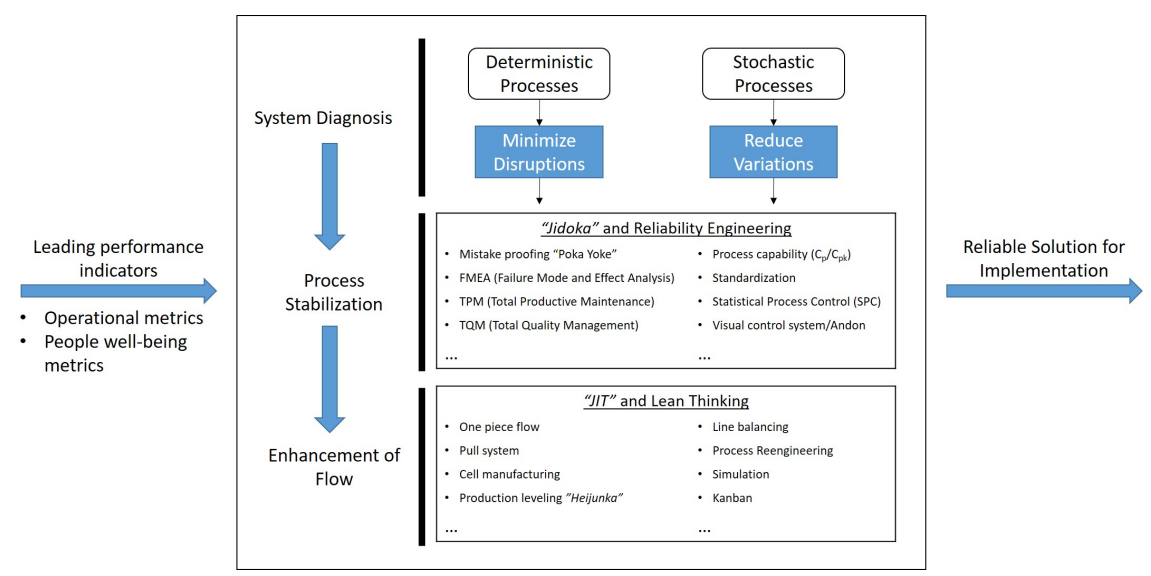

Figure 6. System diagnosis and enhancement via reliability. 
LP initiatives that rely merely in the enhancement of flow. Fast paced working environments have exhibited correlation with injuries and musculoskeletal disorders and fatigue (Conti et al., 2006; Koukoulaki, 2014). Conversely, reliable and stable environments that mitigate disruptions and variability not only foster occupational safety, teamwork engagement and communication (Akram et al., 2016; Sawhney et al., 2010), but also boosts throughput as depicted in the previous module.

\subsubsection{Module 4-Sustain via Employee Buy In}

The final step towards the sustainability of LP, which anticipates employee resistance by mechanisms measuring improvement in their quality of life, is asserted in this module. The objective of designing a sustainable LP practice resides in finding the balance between the perfect operational system and the perfect people system.

Employee resistance can be understood through the lens of culture, basic competence of the workforce, and societal culture. Once all sub factors in each of these categories have been understood, a "people-centric" system design" can emerge from the technical solution, as the mechanism of a "systems thinking" perspective would provide tangible dynamic effects of the technical solution on all stakeholders. Such a design must be iteratively evaluated and adjusted until the perceived resistance to improvements has been eliminated. This approach provides the baseline for a sustainable LP as the new changes are assessed and adjusted placing priority in employees well-being, while attaining the objectives of a learning organization.

A critical driver is the motivation behind the people in the system for the successful accomplishment of these objectives. The proposed model builds its framework with essential factors of people well-being (Figure 7) in accordance with Maslow's Hierarchy of Needs (Maslow, 1943). These factors are called levels of employee work-related needs (Sawhney et al., 2019):

- Level 1: An employee must receive fair compensation and have job security. The perception of LP amongst employees could be detrimental if this level is not satisfied, affecting their performance and participation. This leads to higher turnover rates. A perfect people system must have zero turnover.

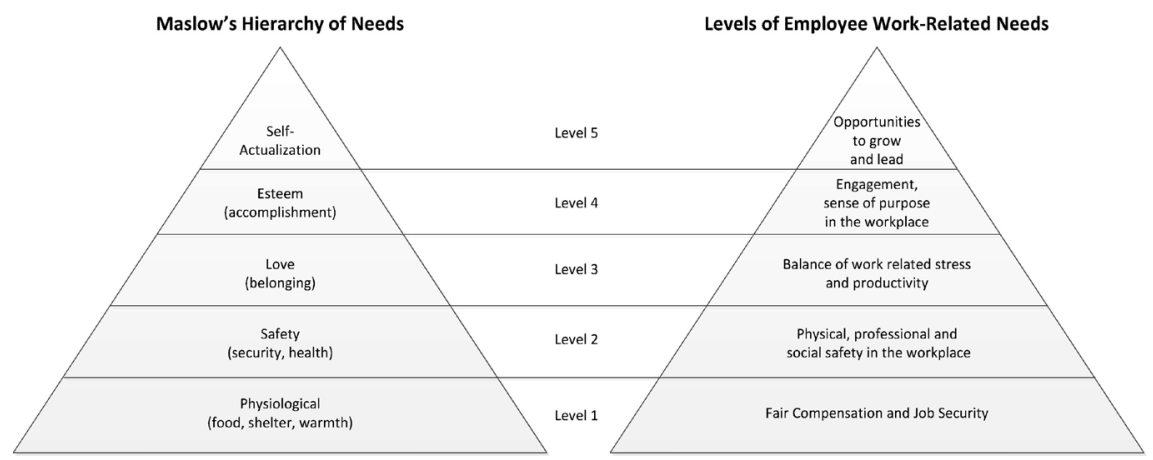

Figure 7. Levels of needs. 
- Level 2: An employee must feel safe in the workplace. Safety has three components: 1) Physical safety, 2) Professional safety, and 3) Social safety which is indicated by the extent of prevalent prejudice or bias. Lean implementations address the first component sufficiently by way of tools such as 5S, visual controls, and mistake proofing. The second and third are not directly addressed in the context of Lean. A perfect people system must have zero recorded safety events related to any component.

- Level 3: An employee must experience a balance of work related stress and productivity. In its absence, employees feel stressed and unreasonable demands may be imposed on their work. A perfect system must have zero levels of stress indicators such as overtime hours, absenteeism, and work backlog.

- Level 4: An employee must be engaged; that is, have a sense of purpose and belonging in the workplace. Engagement of employees in this sense is rarely a component of Lean planning and implementation. A perfect people system must engage employees who experience high levels of autonomy at work.

- Level 5: An employee must have opportunities to grow and lead. The individuals who have earned influence and respect within the organization must get the opportunity to leverage this ability towards the success of the implementation. A perfect people system must identify and promote leaders from within the organization.

Employee engagement is achieved by understanding their different needs. These needs at the same time must consider stress mitigation, development and alignment of skills, and flexibility to adapt to specific cultures. Thus, the sustainability of LP is understood by the effects that affecting individual motivations will have on the system.

The objective to reduce stress is addressed from two perspectives: the simplification of project execution and redesigned activities with engaged people. Project execution is simplified more commonly for LP practitioners at a managerial or supervisory level with the first three modules of the methodology. In complement, engagement occurs when people at the shop floor receives the consideration through each of the Levels of Needs (Figure 7), progressively climbing to the highest level.

The development and alignment of skills is achieved with the identification of the competencies required for the specific tasks and the culture that is being developed within the organization. Certain skills have been identified as desirable within LP employees recruited by Toyota (Liker, 2003), such as adaptability, initiative, mechanical ability, oral communication, practical learning, problem identification, problem solution, team orientation and work tempo. Ideally, these skills can provide a level of certainty that a person integrating into this initiative will develop a higher sense of belonging, higher levels of performance and dependability, and lower risk for departure from the organization.

Consideration of culture involves two aspects: culture of the society, and culture of the generation. As communication technologies evolve, the geographical 
limits have been virtually reduced, but the generational gap has expanded. This occurs in work systems that try to emulate successful practices which were created under specific contingencies. When these contingencies are ignored, a system that works within one context is not guaranteed to provide results in a different one. Hence, this methodology proposes specific methods and models that allow organizations to understand these differences and adjust for a sustainable LP practice.

Moreover, the engagement of the people is reaffirmed by understanding the leverage points that drive their motivation. Recognition (feeling of value) is reinforced by developing autonomy and providing the mechanisms allowing them to grow through each one of the five aforementioned levels.

\section{Theory and Practice Implications}

The proposed model in this study has implications in both theory and practice. With regards to theoretical implications, our model raises novel discussions that have been poorly addressed in previous literature. As one of the key points for a successful change is the understanding of how people and organizations perceive changes when exposed to a transitional environment (McAllaster, 2004), a work perspective supported by LP principles should depend heavily on people's flexibility and involvement. However, most of the existing LP frameworks do not explicitly address people aspects of the change process (Tortorella \& Fogliatto, 2014) and tend to be exclusively training-oriented ( $\mathrm{Li}$ et al., 2014), neglecting people's motivation and engagement throughout its implementation. In this sense, our model bridges this gap by clearly indicating the need for a proper alignment between operational and people perspectives right at the beginning of the LP implementation. Such initial alignment helps to ensure that the benefits obtained from the aimed improvements meet expectations from both organizations and employees, mitigating myopic approaches that are quite likely to fail in the long run. This alignment favors the concurrent consideration of people and organizational motivations before the implementation of improvements reinforcing a higher awareness level about the need for change. This fact enhances engagement and reduces the usual implementation stress and tensions between senior managers and employees.

Regarding practical contributions, this model proposes a problem identification and classification before the application of any LP practice or problem-solving methodology. Each LP practice provides a unique result and should be applied according to a specific need and context (Netland, 2016). In fact, managers and practitioners still struggle with appropriate selection of LP practices and usually choose one or two to start their wide and indiscriminate implementation (Bhasin, 2008). Further, despite the problems faced, most companies often seem to apply a similar path for improvement, which is mainly based on value stream mapping (Marodin \& Saurin, 2013), eliciting a mismatch between problems and solving methods. Hence, the comprehension of the problem nature, determinis- 
tic or stochastic, and its categorization according to existing issues (flow, variation and disruption) enable to address improvements in a more assertive way, avoiding misguided selection of practices and methods that may demand a lot of effort but with low impact on the problem.

In contrast to existing LP implementation models that commonly focus on increasing productivity at the lowest expense of resources, this model proposes a paradigm shift by introducing the concepts of reliability in the design of the system. Hence, the focus is on enhancing the effectiveness of the system as a function of efficiency and reliability-designing a system that will perform its intended function under the specified conditions consistently over time. Furthermore, when supported by a LP model that addresses people's needs, managers may face less resistance from their employees, resulting in a smoother change that leads the organization into the desired performance level while improving the quality of life of its people.

In a general concept, our understanding is that the major theoretical contribution does not come from any specific module, but from the proposition of the people-centric framework as a whole. The sequential propositions of these modules from a system-wide perspective provide guidelines to explicitly approach the underlying method for a successful LP implementation.

\section{Conclusion}

This study aimed at proposing a framework to guide and sustain LP implementations while improving quality of life based on a systematic approach that balances operations' perspectives. The proposed model has been primarily motivated by the identified research gaps in the literature, outlined in the form of four propositions, and complemented by researchers' accrued experience with LP implementation throughout cross-sector organizations. The proposed framework addresses such gaps through a paradigm shift based on the enhancement of reliability of the system supported by four main goals: 1) reduce resource and effort level by strategically defining the problem; 2) align efforts with system growth and competitiveness; 3) enhance capacity via reliability and flow; and 4) enhance employees' quality of life. Besides its academic contribution by adding to the body of such perspective into LP implementation, this study also has practical implications as it provides generalizable LP implementation steps which have not yet emerged.

Future research could perform a more in-depth analysis of each module to validate the envisioned contributions and implications of what is presented in this paper. The shortcomings that would need to be addressed for each module are:

- Module 1: Definition of a standard methodology to identify "the right problem" within the context of LP, and a comparison with models that approach at least one of the following elements:

o Identification of "funneling" strategies that narrow down the scope of the problem, for a precise root-cause analysis. 
o Methods to select the adequate LP toolkit based on the identified problem.

o A process that can be iterative and transferable across sectors.

- Module 2: Structuring of a sub-model that supports a sustainable performance measurement system that includes all of the following characteristics in detail:

o Categorization of indicators according to "typical" organizational units (departments), along with their vertical and horizontal integrations.

o Delineation of leading and lagging indicators and their causal relationships.

o Evidence through theory and practice to affect continuous improvement initiatives.

- Module 3: Consolidation of a definition for variation and disruptions with their corresponding metrics within manufacturing and other sectors. These should address:

o Their impact in the throughput of the system from the perspective of people, materials, equipment and information (PMEI).

o Identification of common failure modes within PMEI, and a robust approach to design for reliability.

- Module 4: Further investigation of a humanistic approach to LP, through the following:

o Standard definition of "quality of life" and how to enhance it within the context of work.

o Convergent approaches for socio-technical systems and LP.

o Common definitions and objective measurement approaches for motivation, engagement, and culture.

These would provide clear directions and steps that aid practitioners and academicians to expand its utilization. To verify its implementation sustainability, the establishment of these longitudinal studies could add insights regarding the real outcomes of the proposed model.

\section{Conflicts of Interest}

The authors declare no conflicts of interest regarding the publication of this paper.

\section{References}

Adler, P. S., Goldoftas, B., \& Levine, D. I. (1997). Ergonomics, Employee Involvement, and the Toyota Production System: A Case Study of Nummi's 1993 Model Introduction. ILR Review, 50, 416-437. https://doi.org/10.1177/001979399705000303

Akao, Y. (1991). Hoshin Kanri: Policy Development for Successful TQM. Cambridge, MA: Productivity Press.

Akram, R., Sawhney, R. S., \& Ganji, V. (2016). Effects of Human Stress on Reliability of Lean Systems: A Markovian Approach. In Proceedings of the International Conference on Industrial Engineering and Operations Management (pp. 420-429). Detroit: IEOM Society.

Alagaraja, M., \& Shuck, B. (2015). Exploring Organizational Alignment-Employee En- 
gagement Linkages and Impact on Individual Performance: A Conceptual Model. $\mathrm{Hu}$ man Resource Development Review, 14, 17-37.

https://doi.org/10.1177/1534484314549455

Almström, P., \& Kinnander, A. (2011). The Productivity Potential Assessment Method Assessing and Benchmarking the Improvement. International Journal of Productivity and Performance Management, 60, 758-770. https://doi.org/10.1108/17410401111167825

Antonelli, D., \& Stadnicka, D. (2018). Combining Factory Simulation with Value Stream Mapping: A Critical Discussion. Procedia CIRP, 67, 30-35. https://doi.org/10.1016/j.procir.2017.12.171

Babson, S. (1993). Lean or Mean: The MIT Model and Lean Production at Mazda. Labor Studies Journal, 18.

Bao, S., Winkel, J., Mathiassen, S. E., \& Shahnavaz, H. (1997). Interactive Effect of Ergonomics and Production Engineering on Shoulder-Neck Exposure-A Case Study of Assembly Work in China and Sweden. International Journal of Industrial Ergonomics, 20, 75-85. https://doi.org/10.1016/S0169-8141(96)00032-7

Belekoukias, I., Garza-Reyes, J. A., \& Kumar, V. (2014). The Impact of Lean Methods and Tools on the Operational Performance of Manufacturing Organisations. International Journal of Production Research, 52, 5346-5366. https://doi.org/10.1080/00207543.2014.903348

Berggren, C. (1991). Are They Unbeatable? Report from a Field Trip to Study Transplants, the Japanese Owned Auto Plants in North America. Stockholm: Royal Institute of Technology.

Bhamu, J., \& Singh Sangwan, K. (2014). Lean Manufacturing: Literature Review and Research Issues. International Journal of Operations \& Production Management, 34, 876-940. https://doi.org/10.1108/IJOPM-08-2012-0315

Bhasin, S. (2008). Lean and Performance Measurement. Journal of Manufacturing Technology Management, 19, 670-684. https://doi.org/10.1108/17410380810877311

Biazzo, S., \& Panizzolo, R. (2000). The Assessment of Work Organization in Lean Production: The Relevance of the Worker's Perspective. Integrated Manufacturing Systems, 11, 6-15. https://doi.org/10.1108/09576060010303622

Bortolotti, T., Boscari, S., \& Danese, P. (2015). Successful Lean Implementation: Organizational Culture and Soft Lean Practices. International Journal of Production Economics, 160, 182-201. https://doi.org/10.1016/j.ijpe.2014.10.013

Brenner, M. D., Fairris, D., \& Ruser, J. (2004). "Flexible" Work Practices and Occupational Safety and Health: Exploring the Relationship between Cumulative Trauma Disorders and Workplace Transformation. Industrial Relations, 43, 242-266. https://doi.org/10.1111/j.0019-8676.2004.00325.x

Bruno, R., \& Jordan, L. (2002). Lean Production and the Discourse of Dissent. Working USA. https://doi.org/10.1111/j.1743-4580.2002.00108.x

Cameron, K. S., \& Quinn, R. E. (2006). Diagnosing and Changing Organizational Culture: Based on the Competing Values Framework. Personnel Psychology, 59, 755-757. https://doi.org/10.1111/j.1744-6570.2006.00052 5.x

Camuffo, A., De Stefano, F., \& Paolino, C. (2017). Safety Reloaded: Lean Operations and High Involvement Work Practices for Sustainable Workplaces. Journal of Business Ethics, 143, 245-259. https://doi.org/10.1007/s10551-015-2590-8

Chay, T., Xu, Y., Tiwari, A., \& Chay, F. (2015). Towards Lean Transformation: The Analysis of Lean Implementation Frameworks. Journal of Manufacturing Technology Man- 
agement, 26, 1031-1052. https://doi.org/10.1108/JMTM-10-2013-0143

Conti, R., Angelis, J., Cooper, C., Faragher, B., \& Gill, C. (2006). The Effects of Lean Production on Worker Job Stress. International Journal of Operations and Production Management, 26, 1013-1038. https://doi.org/10.1108/01443570610682616

Davila, A., \& Elvira, M. M. (2012). Humanistic Leadership: Lessons from Latin America. Journal of World Business, 47, 548-554. https://doi.org/10.1016/j.jwb.2012.01.008

Feld, W. M. (2000). Lean Manufacturing-Tools, Techniques, and How to Use Them. Boca Raton, FL: CRC Press. https://doi.org/10.1201/9781420025538

Forrester, J. W. (1971). World Dynamics. Cambridge, MA: Wright-Allen Press.

Fullerton, R. R., \& Wempe, W. F. (2009). Lean Manufacturing, Non-Financial Performance Measures, and Financial Performance. International Journal of Operations and Production Management, 29, 214-240. https://doi.org/10.1108/01443570910938970

Giordani da Silveira, W., Pinheiro de Lima, E., Deschamps, F., \& Gouvea da Costa, S. E. (2018). Identification of Guidelines for Hoshin Kanri Initiatives. International Journal of Productivity and Performance Management, 67, 85-110. https://doi.org/10.1108/IJPPM-03-2016-0071

Graham, L. (1995). On the Line at Subaru-Isuzu: The Japanese Model and the American Worker. ILR Press.

Gregory, A., \& Milner, S. (2009). Editorial: Work-Life Balance: A Matter of Choice? Gender, Work \& Organization, 16, 1-13. https://doi.org/10.1111/j.1468-0432.2008.00429.x

Härenstam, A., Rydbeck, A., Johansson, K., Karlqvist, M., \& Wiklund, P. (2002). Work Life and Organizational Changes and How They Are Perceived by the Employees. In Health Effects of the New Labour Market (pp. 105-117). Boston: Kluwer Academic Publishers. https://doi.org/10.1007/0-306-47181-7 9

Harrison, B. (1997). Lean and Mean: The Changing Landscape of Corporate Power in the Age of Flexibility. New York: Guilford Press.

Hasle, P., Bojesen, A., Langaa Jensen, P., \& Bramming, P. (2012). Lean and the Working Environment: A Review of the Literature. International Journal of Operations \& Production Management, 32, 829-849. https://doi.org/10.1108/01443571211250103

Hopp, W. J., \& Spearman, M. L. (2008). Factory Physics (2nd ed., pp. 314-331). New York: McGraw-Hill/Irwin.

Jackson, P. R., \& Martin, R. (1996). Impact of Just-in-Time on Job Content, Employee Attitudes and Well-Being: A Longitudinal Study. Ergonomics, 39, 1-16. https://doi.org/10.1080/00140139608964429

Jackson, T. L. (2006). Hoshin Kanri for the Lean Enterprise: Developing Competitive Capabilities and Managing Profit. Boca Raton, FL: CRC Press. https://doi.org/10.4324/9781482278514

Jurburg, D., Viles, E., Tanco, M., \& Mateo, R. (2017). What Motivates Employees to Participate in Continuous Improvement Activities? Total Quality Management and Business Excellence, 28, 1469-1488. https://doi.org/10.1080/14783363.2016.1150170

Keyser, R. S., \& Sawhney, R. S. (2013). Reliability in Lean Systems. International Journal of Quality \& Reliability Management, 30, 223-238. https://doi.org/10.1108/02656711311299818

Khaba, S., \& Bhar, C. (2018). Lean Awareness and Potential for Lean Implementation in the Indian Coal Mining Industry: An Empirical Study. International Journal of Quality 
\& Reliability Management, 35, 1215-1231.

https://doi.org/10.1108/IJQRM-02-2017-0024

Kim, D. H., \& Anderson, V. (1998). Systems Archetype Basics. Waltham, MA: Pegasus Communications Inc.

Kirkwood, C. W. (1998). System Dynamics Methods. College of Business Arizona State University USA.

Koukoulaki, T. (2014). The Impact of Lean Production on Musculoskeletal and Psychosocial Risks: An Examination of Sociotechnical Trends over 20 Years. Applied Ergonomics, 45, 198-212. https://doi.org/10.1016/j.apergo.2013.07.018

Leroyer, A., Kraemer-Heriaud, H., Marescaux, L., \& Frimat, P. (2006). Prospective Evaluation of the Impact of a Change in the Organization of Work on Perceived Stress and Health in Assembly-Line Workers in an Automobile Plant. Revue d'Épidémiologie et de Santé Publique, 54, 15-25. https://doi.org/10.1016/S0398-7620(06)76691-3

Lewchuk, W., \& Robertson, D. (1996). Working Conditions under Lean Production: A Worker-Based Benchmarking Study. Asia Pacific Business Review, 2, 60-81. https://doi.org/10.1080/13602389600000020

Lewchuk, W., \& Robertson, D. (1997). Production without Empowerment: Work Reorganization from the Perspective of Motor Vehicle Workers. Capital \& Class, 21, 37-64. https://doi.org/10.1177/030981689706300104

Lewchuk, W., Stewart, P., \& Yates, C. (2001). Quality of Working Life in the Automobile Industry: A Canada-UK Comparative Study. New Technology, Work and Employment, 16, 72-87. https://doi.org/10.1111/1468-005X.00078

Li, J., \& Meerkov, S. M. (2000). Bottlenecks with Respect to Due-Time Performance in Pull Serial Production Lines. Mathematical Problems in Engineering, 5, 479-498. https://doi.org/10.1155/S1024123X99001209

Li, Y., Sawhney, R. S., \& Wilck IV, J. H. (2014). Prioritizing Lean Six Sigma Efforts Using Bayesian Networks. In Analytical Approaches to Strategic Decision-Making: Interdisciplinary Considerations (pp. 77-91). Hershey, PA: IGI Global. https://doi.org/10.4018/978-1-4666-5958-2.ch005

Liker, J. (2003). The Toyota Way. New York: McGraw-Hill.

Little, J. D. (1961). A Proof for the Queuing Formula: L $=\lambda$ W. Operations Research, 9, 383-387. https://doi.org/10.1287/opre.9.3.383

Lloyd, C., \& James, S. (2008). Too Much Pressure? Retailer Power and Occupational Health and Safety in the Food Processing Industry. Work, Employment and Society, 22, 713-730. https://doi.org/10.1177/0950017008098366

Losonci, D., Demeter, K., \& Jenei, I. (2011). Factors Influencing Employee Perceptions in Lean Transformations. International Journal of Production Economics, 131, 30-43. https://doi.org/10.1016/j.ijpe.2010.12.022

Lucey, J., Bateman, N., \& Hines, P. (2005). Why Major Lean Transitions Have Not Been Sustained. Management Services, 49, 9-13.

Marodin, G. A., \& Saurin, T. A. (2013). Implementing Lean Production Systems: Research Areas and Opportunities for Future Studies. International Journal of Production Research, 51, 6663-6680. https://doi.org/10.1080/00207543.2013.826831

Maslow, A. H. (1943). A Theory of Human Motivation. Psychological Review, 50, 370. https://doi.org/10.1037/h0054346

Matias, J. C. O., Govindan, K., Pimentel, C., Pinto, J. L. Q., \& Azevedo, S. G. (2018). Just in Time Factory. Implementation through Lean Manufacturing Tools (pp. 39-112). 
Cham: Springer. https://doi.org/10.1007/978-3-319-77016-1 4

McAllaster, C. M. (2004). The 5 P's of Change. Organizational Dynamics, 3, 318-328. https://doi.org/10.1016/j.orgdyn.2004.06.008

Mehri, D. (2006). The Darker Side of Lean: An Insider's Perspective on the Realities of the Toyota Production System. Academy of Management Perspectives, 20, 21-42. https://doi.org/10.5465/amp.2006.20591003

Melé, D. (2016). Understanding Humanistic Management. Humanistic Management Journal, 1, 33-55. https://doi.org/10.1007/s41463-016-0011-5

Monden, Y. (2011). Toyota Production System: An Integrated Approach to Just-in-Time. Boca Raton, FL: CRC Press.

Muffatto, M. (1999). Evolution of Production Paradigms: The Toyota and Volvo Cases. Integrated Manufacturing Systems, 10, 15-25. https://doi.org/10.1108/09576069910247564

Mullarkey, S., Jackson, P. R., \& Parker, S. K. (1995). Employee Reactions to JIT Manufacturing Practices: A Two-Phase Investigation. International Journal of Operations \& Production Management, 15, 62-79. https://doi.org/10.1108/01443579510102909

Mumford, E. (2006). The Story of Socio-Technical Design: Reflections on Its Successes, Failures and Potential. Information Systems Journal, 16, 317-342.

https://doi.org/10.1111/j.1365-2575.2006.00221.x

Narayanamurthy, G., \& Gurumurthy, A. (2016). Leanness Assessment: A Literature Review. International Journal of Operations and Production Management, 36, 1115-1160. https://doi.org/10.1108/IJOPM-01-2015-0003

Netland, T. H. (2016). Critical Success Factors for Implementing Lean Production: The Effect of Contingencies. International Journal of Production Research, 54, 2433-2448. https://doi.org/10.1080/00207543.2015.1096976

Ohno, T. (1988). Toyota Production System: Beyond Large-Scale Production. Cambridge, MA: Productivity Press.

Parker, S. K. (2003). Longitudinal Effects of Lean Production on Employee Outcomes and the Mediating Role of Work Characteristics. Journal of Applied Psychology, 88, 620-634. https://doi.org/10.1037/0021-9010.88.4.620

Pavnascar, S. J., Gershenson, J. K., \& Jambekar, A. B. (2003). Classification Scheme for Lean Manufacturing Tools. International Journal of Production Research, 41, 3075-3090. https://doi.org/10.1080/0020754021000049817

Puvanasvaran, A. P., Muhamad, M. R., Megat, M. H. M. A., Tang, S. H., \& Hamouda, A. M. S. (2008). A Review of Problem Solving Capabilities in Lean Process Management. https://doi.org/10.3844/ajassp.2008.504.511

Russell, R. S., \& Taylor, B. W. (2006). Operations Management (3rd ed.). Upper Saddle River, NJ: Prentice Hall.

Saad, N. M., Al-Ashaab, A., Shehab, E., \& Maksimovic, M. (2013). A3 Thinking Approach to Support Problem Solving in Lean Product and Process Development. In Concurrent Engineering Approaches for Sustainable Product Development in a Multi-Disciplinary Environment (pp. 871-882). Berlin: Springer. https://doi.org/10.1007/978-1-4471-4426-7 74

Saad, S., Perera, T., Achanga, P., Shehab, E., Roy, R., \& Nelder, G. (2006). Critical Success Factors for Lean Implementation within SMEs. Journal of Manufacturing Technology Management, 17, 460-471. https://doi.org/10.1108/17410380610662889

Saurin, T. A., \& Ferreira, C. F. (2009). The Impacts of Lean Production on Working Con- 
ditions: A Case Study of a Harvester Assembly Line in Brazil. International Journal of Industrial Ergonomics, 39, 403-412. https://doi.org/10.1016/j.ergon.2008.08.003

Sawhney, R. S., \& De Anda, E. M. (2016). Sawhney Lean Educational Maturity Model at the University of Tennessee. In A. C. Alves, S. Flumerfelt, \& F.-J. Kahlen (Eds.), Lean Education: An Overview of Current Issues (pp. 99-124). Cham: Springer International Publishing. https://doi.org/10.1007/978-3-319-45830-4 8

Sawhney, R., \& Chason, S. (2005). Human Behavior Based Exploratory Model for Successful Implementation of Lean Enterprise in Industry. Performance Improvement Quarterly, 18, 76-96. https://doi.org/10.1111/j.1937-8327.2005.tb00334.x

Sawhney, R., Pradhan, N., Matias, N., De Anda, E. M., Araujo, E., Trevino, S., \& Arbogast, C. (2019). Teaching Sustainable Lean: The Next Step towards Inculcating a Critical Problem-Solving Mindset. In A. C. Alves, F.-J. Kahlen, S. Flumerfelt, \& A. B. Siriban-Manalang (Eds.), Lean Engineering for Global Development (pp. 61-94). Cham: Springer International Publishing. https://doi.org/10.1007/978-3-030-13515-7 3

Sawhney, R., Subburaman, K., Sonntag, C., Venkateswara Rao, P. R., \& Capizzi, C. (2010). A Modified FMEA Approach to Enhance Reliability of Lean Systems. International Journal of Quality and Reliability Management, 27, 832-855. https://doi.org/10.1108/02656711011062417

Scherrer-Rathje, M., Boyle, T. A., \& Deflorin, P. (2009). Lean, Take Two! Reflections from the Second Attempt at Lean Implementation. Business Horizons, 52, 79-88. https://doi.org/10.1016/j.bushor.2008.08.004

Schouteten, R., \& Benders, J. (2004). Lean Production Assessed by Karasek's Job Demand-Job Control Model. Economic and Industrial Democracy, 25, 347-373. https://doi.org/10.1177/0143831X04044831

Senge, P. M. (2006). The Fifth Discipline: The Art and Practice of the Learning Organization. Broadway Business.

Sezen, B., Karakadilar, I. S., \& Buyukozkan, G. (2012). Proposition of a Model for Measuring Adherence to Lean Practices: Applied to Turkish Automotive Part Suppliers. International Journal of Production Research, 50, 3878-3894.

https://doi.org/10.1080/00207543.2011.603372

Shah, R., \& Ward, P. T. (2003). Lean Manufacturing: Context, Practice Bundles, and Performance. Journal of Operations Management, 21, 129-149. https://doi.org/10.1016/S0272-6963(02)00108-0

Shook, J. (2008). Managing to Learn: Using the A3 Management Process to Solve Problems, Gain Agreement, Mentor and Lead. Cambridge, MA: Lean Enterprise Institute.

Smeds, R. (1994). Managing Change towards Lean Enterprises. International Journal of Operations and Production Management, 14, 66-82. https://doi.org/10.1108/01443579410058531

Spear, S. J. (2009). Chasing the Rabbit: How Market Leaders Outdistance the Competition and How Great Companies Can Catch up and Win. New York: McGraw Hill.

Spear, S., \& Bowen, H. K. (1999). Decoding the DNA of the Toyota Production System. Harvard Business Review, 77, 96-106.

Spithoven, A. H. G. M. (2001). Lean Production and Disability. International Journal of Social Economics, 28, 725-741. https://doi.org/10.1108/EUM0000000005690

Sprigg, C. A., \& Jackson, P. R. (2006). Call Centers as Lean Service Environments: Job-Related Strain and the Mediating Role of Work Design. Journal of Occupational Health Psychology, 11, 197-212. https://doi.org/10.1037/1076-8998.11.2.197 
Sterman, J. D. (2002). System Dynamics Modeling: Tools for Learning in a Complex World. IEEE Engineering Management Review, 43, 8-25.

https://doi.org/10.1109/EMR.2002.1022404

Tortorella, G. L., \& Fogliatto, F. S. (2014). Method for Assessing Human Resources Management Practices and Organisational Learning Factors in a Company under Lean Manufacturing Implementation. International Journal of Production Research, 52, 4623-4645. https://doi.org/10.1080/00207543.2014.881577

Tortorella, G. L., Marodin, G. A., Fogliatto, F. S., \& Miorando, R. (2015). Learning Organisation and Human Resources Management Practices: An Exploratory Research in Medium-Sized Enterprises Undergoing a Lean Implementation. International Journal of Production Research, 53, 3989-4000. https://doi.org/10.1080/00207543.2014.980462

Turesky, E. F., \& Connell, P. (2010). Off the Rails: Understanding the Derailment of a Lean Manufacturing Initiative. Organisation Management Journal, 7, 110-132. https://doi.org/10.1057/omj.2010.14

Vendramin, P., Valenduc, G., Rolland, I., Richardson, R., Gillespie, A., Belt, V., \& Seveso, P. (1998). Flexible Work Practices and Communication Technology FLEXCOT Coordinator of Project.

Womack, J. P. and Jones, D. T. (1994). From Lean Production to the Lean Enterprise. Harvard Business Review, 72, 93-103.

Womack, J. P., \& Jones, D. T. (1990). The Machine That Changed the World. New York: Simon and Schuster.

Yadav, O. P., Nepal, B. P., Rahaman, M. M., \& Lal, V. (2017). Lean Implementation and Organizational Transformation: A Literature Review. Engineering Management Journal, 29, 2-16. https://doi.org/10.1080/10429247.2016.1263914

Yang, T., \& Hsieh, C. H. (2009). Six-Sigma Project Selection Using National Quality Award Criteria and Delphi Fuzzy Multiple Criteria Decision-Making Method. Expert Systems with Applications, 36, 7594-7603. https://doi.org/10.1016/j.eswa.2008.09.045

Zhou, B. (2016). Lean Principles, Practices, and Impacts: A Study on Small and Medium-Sized Enterprises (SMEs). Annals of Operations Research, 241, 457-474.

https://doi.org/10.1007/s10479-012-1177-3 